\title{
Análise do perfil dos médicos condenados à cassação do exer- cício profissional no Estado de São Paulo: questões bioéticas
}

\section{Analysis of the profile of medical doctors condemned license revocation in the State of São Paulo: bioethical questions}

\author{
José Marques Filho \\ Conselho Regional de Medicina do Estado de São Paulo (CREMESP), São \\ Paulo, Brasil. \\ filho.jm@bol.com.br
}

\author{
William Saad Hossne \\ Centro Universitário São Camilo, São Paulo, Brasil. \\ cem@fmb.unesp.br
}

Resumo: Objetivou-se, à luz da bioética, analisar o perfil dos médicos condenados à cassação do exercício profissional no Estado de São Paulo, Brasil. Foram realizadas leitura e análise das atas oficiais da plenária do Conselho Regional de Medicina do Estado de São Paulo (CREMESP) e dos autos dos processos que resultaram em cassação do exercício profissional no período de Janeiro de 1988 a dezembro de 2004. Para a caracterização do perfil dos médicos foram considerados os seguintes dados: idade, sexo, faculdade de origem, tempo de formado, área de atuação, cursos de pós-graduação e antecedentes de processos ético-profissionais. A idade média foi de 45,7 anos, o tempo médio de formado foi de 16,6 anos, todos os médicos eram do sexo masculino, a área de atuação mais freqüente foi a clinica médica, 48,8\% dos médicos não tinham cursos de especialização ou residência médica e aproximadamente metade deles tinham antecedentes de processo no CREMESP. Os dados obtidos demonstram a importância da reflexão bioética nos processos que resultaram em cassação do exercício profissional e a necessidade do ensino de Bioética nos cursos de graduação, pós-graduação e educação médica continuada.

Palavras-chave: Bioética. Ética. Perfil de médicos. Cassação do exercício professional.

\begin{abstract}
This study sought to analyze, under the perspectives of bioethics, the characteristics of the physicians to have their license revoked by the Regional Board of Medicine of State of São Paulo, Brazil. The official minutes of this organization's plenary sessions as well as files from the processes that resulted in the revocation of medical license between January 1988 and De-
\end{abstract}


cember 2004 were carefully read and analyzed. The data chosen for analysis were: age, gender, university from which the degree was obtained, the time since graduation, the field of activity, post-graduate coursework, and antecedent ethical-professional suits. The average age was 45.7 years, the average time since graduation was 16.6 years, all the convicted physicians were male, the medical clinic area was the most common field of activity, $48.8 \%$ of the convicted physicians didn't undertake residency internships or post-graduate education, and approximately half had antecedent suits in the regulatory organization. The data collected demonstrate the importance of Bioethics in the processes that result in license revocation and of teaching Bioethics in graduate, post-graduate and continuing medical education.

Key-words: Bioethics. Ethics. Profile of medical doctors. License revocation.

A profissão médica é uma das mais antigas do mundo. Surgiu quando alguém sentiu dor e, pela primeira vez, outra pessoa solidariamente postou-se ao seu lado e lhe estendeu a mão (1). A prática da arte médica tem origem em tempos primitivos, entretanto, a ciência médica, como a conhecemos hoje, não tem mais de dois séculos.

Fávero (2) divide a história da medicina em três períodos: religioso ou antigo, filosófico e científico ou moderno. Segundo o autor, antes do período religioso o que existiu foi uma era nebulosa de magia e feitiçaria dos homens da caverna. Já no período religioso a medicina era exercida por sacerdotes, médicos do corpo e da alma, praticada em templos e cultos. No período filosófico surge Hipócrates, oriundo do ramo dos médicos sacerdotes asclepíades; é considerado o pai da medicina, e seu juramento, paradigma maior da arte médica, preconiza diversos princípios éticos, pilares da prática médica até os nossos dias. Finalmente, no científico ou moderno, em que os princípios tradicionais da ética têm sido por vezes negligenciados, inevitavelmente é imprescindível o aguilhão de uma sanção punitiva.

Até um passado não muito distante, a prática médica era revestida de uma aura divina, tida como verdadeiro sacerdócio, protegendo seus praticantes, a ponto de seus atos e resultados não serem submetidos a julgamento. Não havia razão para se discutir os desígnios dos esculápios, pois estes eram verdadeiros intermediários da vontade divina.

A ética medica tem tradição milenar e, se Hipócrates é considerado até hoje o mestre mais importante da ética médica, não se pode 
olvidar a fundamental importância de Thomas Percival, cuja obra Medical Ethics de 1803 (3), serviu de base para a legislação ética de diversos países do ocidente, incorporando à normativa ética novos paradigmas diante dos avanços científicos e tecnológicos.

Os princípios éticos e morais da profissão médica caracterizam uma ciência, a deontologia médica. Do grego deon (dever) e logos (estudo), a deontologia é a ciência do dever ou das obrigações médicas. Por outro lado, a diceologia - dikeus (direito) e logos (estudo) - é a codificação dos direitos profissionais. Segundo Segre (4), dentro do conceito clássico pode-se denominar a deontologia médica de moral médica.

Martin (5), discutindo os direitos humanos nos códigos de ética médica brasileiros em uma perspectiva histórica, relata que boa parte dos códigos se concentrava em assuntos ligados ao comportamento pessoal do médico, na relação com seus pacientes e colegas. Somente pouco a pouco temas como direitos humanos, doação e transplantes de órgãos e ética em pesquisa entram nos códigos e começam a alargar horizontes. De fato, à luz dessa observação, podem-se detectar duas tendências na área de ética médica. Uma que restringe a ética a uma deontologia profissional, que se preocupa com a moral do médico e seu decoro profissional e outra que assume uma postura mais acolhedora da realidade. Esta tendência acolhedora é responsável pela construção de uma ética médica propensa à influência da Bioética.

Esta postura aberta à bioética é a marca que caracteriza os diplomas éticos brasileiros a partir da década de 80 do século passado, particularmente o Código de Ética Médica atual, vigente desde 1988 (6).

O Conselho Federal e os Conselhos Regionais de Medicina são autarquias federais criados por lei especifica (7), com exclusividade para fiscalizar o exercício profissional e julgar as infrações éticas cometidas pelos médicos que exercem regularmente a profissão em nosso país. Diante da gravidade da falta cometida e em situações de risco para a sociedade, esses Conselhos têm a competência exclusiva de suspender ou cassar a licença do exercício profissional.

A pena de cassação do exercício profissional, com referendo obrigatório do Conselho Federal de Medicina, é uma das ações mais difíceis e importantes dos Conselhos Regionais de Medicina. Esta decisão ocorre em um cenário rico e carregado de aspectos emocionais, envolvendo as partes e o corpo de conselheiros. 
Aspectos de natureza bioética estão envolvidos em todas as fases que resultam em cassação do exercício profissional, desde a formação básica acadêmica do médico, passando pelos valores morais dos profissionais que exercem a arte médica, até na legitimidade da lide e de todo o ritual que caracteriza o processo ético-profissional.

Neste sentido, posturas e reflexões de caráter bioético necessariamente permeiam todas as etapas dos processos ético-profissionais. Os referenciais bioéticos (autonomia, beneficência, não maleficência, justiça, competência, prudência, vulnerabilidade, solidariedade) adquirem especial relevância no julgamento e avaliação de processos de cassação do exercício profissional (8).

O objetivo deste estudo foi conhecer o perfil dos médicos condenados à cassação da licença para o exercício profissional, para a devida discussão e reflexão, sobretudo de natureza bioética, procurando delinear medidas preventivas.

\section{Método}

O material de estudo consistiu na análise dos autos dos processos ético-profissionais e das atas oficiais da plenária do Conselho Regional de Medicina do Estado de São Paulo (CREMESP), Brasil. O período determinado foi de janeiro de 1988 a dezembro de 2004. Esta opção foi devida ao fato do atual Código de Ética Médica ter entrado em vigor em janeiro de 1988, possibilitando a padronização dos dados.

Para cada processo analisado, os dados dos médicos envolvidos foram coletados através de um protocolo específico para este estudo. Para a caracterização do perfil dos médicos condenados à cassação do exercício profissional pelo CREMESP foram considerados os seguintes dados: idade, sexo, faculdade de origem, tempo do exercício profissional, área médica de atuação, título de especialista, residência médica, pós-graduação e antecedentes de processos ético-profissionais no CREMESP.

A idade do médico e o tempo de exercício profissional foram aqueles anotados na ocasião dos fatos. As faculdades cursadas pelos profissionais foram divididas em: pertencentes ao Estado de São Paulo, pertencentes a outros Estados da Federação e do exterior. Foram também classificadas em públicas e privadas. Foi considerada como 
área de atuação a área habitual de atuação profissional declarada pelo próprio médico em suas manifestações no processo ético-profissional ou decidido pelo pesquisador após leitura dos autos. Optou-se, por exemplo, classificar como clínico tanto os especialistas desta área médica, quanto aqueles que se intitulavam generalistas e/ou praticante de medicina interna, termos que foram usados por longos anos em nosso meio. Foi considerado portador de título de especialista o médico que confirmou, na época dos fatos, titulação obtida por concurso realizado pela respectiva sociedade de especialidade. Em relação ao curso de residência médica foram considerados aqueles credenciados pelo Ministério da Educação.

Um dos autores, conselheiro do CREMESP durante três gestões, selecionou os processos e participou diretamente do julgamento de 35 médicos $(77,7 \%)$ condenados à pena e cassação do exercício profissional.

Todas as providências no sentido de preservar a confidencialidade dos autos e o sigilo processual foram cuidadosamente observadas.

\section{Resultados}

Entre janeiro de 1988 a dezembro de 2004, período estabelecido para este estudo, foram analisados 41 processos ético-profissionais. Nesses processos pode haver um ou mais médicos envolvidos. $\mathrm{Na}$ análise feita, o resultado foi a condenação de 45 médicos à pena máxima, a cassação do exercício profissional pelo CREMESP, com o respectivo julgamento pelo Conselho Federal de Medicina. Esses resultados podem ser encontrados na dissertação de Marques Filho (9).

A média de idade verificada foi de 45,7 anos, sendo a mínima de 28 anos e a máxima de 66 anos. Quando distribuídos por faixa etária observa-se que abaixo dos 30 anos apenas 2 médicos (4,5\%) foram condenados, entre 31 e 40 anos , 12 médicos (26,6\%); entre 41 e 50 anos, 17 médicos $(37,7 \%)$; entre 51 e 60 anos, 10 médicos $(22,2 \%)$ e maior que 61 anos, 4 médicos $(8,8 \%)$ foram condenados. Quanto ao sexo dos 45 médicos julgados e condenados, observou-se que todos $(100 \%)$ eram do sexo masculino

Em relação às faculdades cursadas pelos profissionais, observouse que 11 médicos $(24,4 \%)$ eram oriundos de faculdades públicas do 
Estado de São Paulo; 12 médicos $(26,6 \%)$ eram de faculdades privadas do Estado de São Paulo; 12 médicos (26,6\%) provinham de faculdades públicas de outros Estados; 6 médicos (13,3\%) eram de faculdades privadas de outros Estados e 4 médicos $(8,8 \%)$ foram formados em faculdades do exterior.

Quanto ao tempo de formado dos médicos condenados, observou-se uma média de 16,6 anos, sendo o mínimo de um ano e o máximo de 36 anos. Quando dividido em faixas por tempo de formado, observou-se que 4 médicos $(8,8 \%)$ tinham menos de 5 anos de formado; 7 médicos (15,5\%) tinham entre 6 e 10 anos de formado; 12 médicos (26,6\%) entre 11 e 15 anos; 8 médicos $(17,7 \%)$ entre 16 e 20 anos; 6 médicos (13,3\%) entre 21 e 25 anos; e 8 médicos $(17,7 \%)$ mais que 25 anos de formado.

Em relação à área de atuação, a mais freqüente foi clínica médica, com 15 médicos (33,3\%); a seguir a ginecologia e obstetrícia, com 10 médicos $(22,2 \%)$; cirurgia, com 6 médicos $(13,3 \%)$; medicina legal, com 3 médicos (6,6\%); endocrinologia, com 3 médicos $(6,6 \%)$;ortopedia, com 2 médicos $(4,4 \%)$; e geriatria, cardiologia, medicina intensiva, reumatologia, psiquiatria e anestesiologia, todas com 1 médico $(2,2 \%)$.

Quanto à titulação dos 45 médicos condenados, 15 (33,3\%) deles tinham o título de especialista na área que atuavam; $8(17,7 \%)$ tinham residência médica comprovada. Os outros 22 médicos $(48,8 \%)$ não tinham nenhum curso ou título de especialização após sua formação básica. Nenhum médico condenado à pena máxima tinha curso de pós-graduação stricto sensu.

Em relação ao antecedente de processos ético-profissional no CREMESP, isto é, processos em andamento e/ou já concluídos e julgados antes da cassação do exercício profissional, 24 médicos $(53,3 \%)$ não tinham antecedentes, os outros 21 médicos tinham antecedente assim distribuídos: 1 processo - 13 médicos $(25,5 \%)$; 2 processos -4 médicos $(8,8 \%) ; 3$ processos -3 médicos $(6,4 \%)$; mais que 4 processos - 1 médico $(2,2 \%)$.

\section{Discussão}

A cassação do exercício profissional de médico é tema constante e altamente relevante, seja no meio acadêmico ou na mídia em geral. 
Nas publicações da área de ética biomédica, a cassação do exercício profissional é tema freqüentemente citado, porém pouco estudado. Em geral, é abordado do ponto de vista puramente teórico. Diante disso, parece oportuno elaborar a discussão e reflexão de caráter bioético sobre dados concretos, e este foi o nosso objetivo básico: colher os dados e as informações dos processos ético-profissionais que resultaram em cassação da licença médica e discuti-los à luz da bioética.

A ética médica e a deontologia não podem ser confundidas com Bioética, embora sejam partes integrantes desta.

Em relação ao perfil do médico condenado à pena máxima, observou-se que cerca de dois terços têm menos que 50 anos de idade, (idade média de 45,7 anos). Esses dados são semelhantes aos de outros estudos. Boyaciyan (10) observou que cerca de dois terços dos ginecologistas e obstetras que responderam a processo ético-profissional no Estado de São Paulo estão abaixo dos 45 anos, resultados semelhantes aos relatados por D'Avila (11) para os médicos que responderam a processos ético-profissionais no Estado de Santa Catarina.

Quanto ao tempo de formado, observou-se que a faixa mais freqüente foi de 11 a 15 anos, com média de 16.6 anos. Esses dados são semelhantes a outros estudos realizados com médicos que responderam a processos ético-profissionais em geral $(10,11,12,13)$.

É possível que a baixa freqüência antes de cinco anos de formado se deva ao período de aperfeiçoamento (residência médica e especialização) e após os vinte e cinco anos a uma menor atividade profissional.

Os dados deste estudo demonstram que todos os profissionais condenados à pena de cassação do exercício profissional eram do sexo masculino.

De acordo com o Centro de Dados do CREMESP (14), em 1959 o número de médicos que atuavam no estado de São Paulo era de 7480 profissionais, sendo que $95 \%$ eram do sexo masculino e $5 \%$ do sexo feminino. Em 2005 esse número aumentou para 84101 médicos, sendo $63 \%$ do sexo masculino e $37 \%$ do sexo feminino. Observa-se um aumento significativo na participação da mulher na prática médica; não obstante, não houve cassação de médicas no período estudado.

Esta tendência de menor freqüência de condenações em processos éticos de profissionais do sexo feminino foi confirmada por di- 
versos autores, entre eles, Morrison e Wilkersham (15), nos EUA, e Falcão (16) e Maia (12), no Brasil.

É possível que a natureza e a gravidade dos fatos que motivaram a cassação do exercício profissional tenham ocorrido em setores com maior número de profissionais do sexo masculino, como por exemplo, cargos de direção de instituições. Pode-se invocar também que valores próprios da condição feminina interfiram na freqüência de participação de profissionais do sexo feminino nos atos médicos passiveis de condenação à pena máxima (prática de aborto, por exemplo).

Outra suposição possível, amparada por uma perspectiva bioética, seria a de que o comportamento da mulher na relação médicopaciente tenha um caráter mais acolhedor e que o comportamento ético no exercício da profissão seja mais adequado quando se faz uma reflexão de gênero. Alguns referenciais bioéticos, como por exemplo, a prudência e a solidariedade, são virtudes que caracterizam a práxis feminina em todas as atividades e, particularmente, em relação à prática da arte médica, onde estes referenciais determinam uma relação terapêutica com grande diferencial de qualidade.

Quanto à faculdade de origem dos médicos condenados, observou-se um equilíbrio, entre os oriundos de faculdades públicas e os de faculdades privadas. A ética médica e a bioética são disciplinas que tem em geral pequena carga horária nas faculdades de medicina, não obstante o reconhecimento crescente da importância das mesmas para a formação médica.

Por outro lado, supõe-se também que a conduta ética está mais diretamente relacionada aos exemplos que com as aulas formais no curso de graduação. Assim, a formação ética do corpo docente é, a nosso ver, um ponto crítico no processo de formação ética do estudante de medicina. É de se supor que a conduta ética do aluno depende tanto do seu caráter quanto da qualidade de ensino.

Em nossa casuística quase metade $(48,8 \%)$ dos médicos condenados à pena máxima não possuíam curso de pós-graduação oficialmente reconhecido ou tinham título de especialista. Atualmente a residência médica, devido às deficiências curriculares, é uma extensão do curso básico, praticamente obrigatória. Os cursos de especialização, de residência médica e pós-graduação oferecem, pelo menos teoricamente, maiores oportunidades para melhor formação técnica e 
ética do médico.

A clínica médica foi a área de atuação mais comum entre os profissionais condenados. Este dado contrasta com outros estudos, referentes a processos ético-profissionais em geral, onde a obstetrícia e ginecologia foram as áreas de atuação mais citadas $(11,16,17)$.

Aproximadamente metade dos médicos que foram punidos com a pena máxima já tinham antecedentes de processos ético-profissionais no CREMESP. Em determinados casos, a reincidência tem peso importante na decisão de cassação do exercício profissional, como por exemplo, nos casos relacionados a assédio sexual.

Os dados obtidos evidenciam a relevância da reflexão bioética neste tema. A vulnerabilidade da população é o referencial bioético a ser protegido, enquanto a justiça é o referencial fundamental nos procedimentos disciplinares dos conselhos.

A reflexão e o ensino da bioética devem necessariamente fazer parte do currículo da graduação médica, dos cursos de pós-graduação e especialmente educação médica continuada (profissionais no exercício da medicina), visando a prevenção das faltas éticas que atingem a sociedade na área de atenção à saúde, tanto no sentido individual como coletivo. Para atingir seus objetivos, o ensino da bioética deve ser realizado ao longo do curso de graduação, sempre associado ao ensino prático da atuação médica, envolvendo o corpo discente e o corpo docente.

Na realidade, no caso da ética em geral, e da bioética em particular, há que se falar mais em educação (como processo formativo) aliada ao ensino (como processo informativo), materializadas nos exemplos oferecidos pelos órgãos formadores e pelos educadores.

\section{Referências}

1. Moura Fé A. Prefácio. In: França VG. Comentários ao Código de Ética Médica. $3^{\mathrm{a}}$ ed. Rio de Janeiro: Guanabara Koogan; 2000. p.VII-XI.

2. Fávero F. Noções de deontologia médica e medicina profissional. Rio de Janeiro: Pimenta de Melo; 1932.

3. Percival T. Medical ethics. Manchester: S. Russell; 1803.

4. Segre M. Definição de bioética e sua relação com a ética, deontologia e diceologia. In: Segre M, Cohen C, editores. Bioética. São Paulo: Edusp; 1995. 
5. Martin LM. Os direitos humanos nos códigos brasileiros de ética médica. São Paulo: Loyola; 2002.

6. Brasil. Resolução CFM no 1.246 , de 8 de janeiro de 1988. Dispõe sobre o Código de Ética Médica. Diário Oficial da União; DF 26 jan, 1988.

7. Brasil. Lei $n^{\circ} 3268$, de 30 de setembro de 1957. Dispõe sobre os Conselhos de Medicina e dá outras providências. Diário Oficial da União, DF, 26 jan., 1958.

8. Hossne WS. Bioética: princípios ou referenciais? O Mundo da Saúde $2006 ; 30(4): 673-6$.

9. Marques Filho J. A pena máxima: cassação do exercício profissional médico - Análise, sob o olhar da Bioética, dos processos de cassação do Conselho Regional de Medicina do Estado de São Paulo (dissertação). São Paulo (SP): Centro Universitário São Camilo; 2006.

10. Boyaciyan K. O perfil e as infrações ético-profissionais dos médicos denunciados que exercem ginecologia e obstetrícia no Estado de São Paulo (tese). São Paulo (SP): Universidade Federal de São Paulo; 2005.

11. D'Avila RL. O comportamento ético-profissional dos médicos de Santa Catarina: uma analise dos processos ético-profissionais no período de 1958 a 1996 (dissertação). Florianópolis (SC): Universidade de Santa Catarina; 1998.

12. Maia DB. Erro médico no Brasil: análise de processos ético-profissionais julgados pelo Conselho Federal de Medicina no período de 1988 a 1998 (monografia). Maranhão (MA): Universidade Federal do Maranhão; 1999. 13. Hossne WS. Infrações éticas e penalidades públicas aplicadas aos médicos do Estado de São Paulo (1998-2002). O Mundo da Saúde 2004; 28(3): 258-65.

14. Brasil. Resolução $n^{\circ} 119$, de 5 de julho de 2005. Dispõe sobre a criação do Centro de Dados do CREMESP Diário Oficial do Estado; Poder Executivo, São Paulo, 2 ago, 2005.

15. Morrison J, Wilkersham P Physicians disciplined by State Medical Board. JAMA 1998; 279: 1889-93.

16. Falcão MSSA. A ética e suas infrações: um estudo sobre os processos ético-profissionais do Estado do Rio de Janeiro (dissertação). Rio de Janeiro (RJ): Escola de Saúde Pública da Fundação Instituto Osvaldo Cruz; 1993. 17. Montoya SD, André RP, Victor VP, Jorge LC. Querellas por responsabilidade médica según especialidades en Chile. Rev Assoc Méd Chile 1993; 121: 396-402. 